\title{
ANÁLISE DO TRANSCRIPTOMA DE GENES LIGADOS AO METABOLISMO DE XILOSE NA LEVEDURA LIPOMYCES STARKEYI, DURANTE FERMENTAÇÃO EM FRASCOS AGITADOS.
}

\author{
A. L.V. CORADINI ${ }^{1}$, A.C. DECKMANN ${ }^{2}$, G.S. TEIXEIRA ${ }^{2}$ e T. T. FRANCO ${ }^{1}$ \\ ${ }^{1}$ Universidade Estadual de Campinas, Faculdade de Engenharia Química. \\ ${ }^{2}$ Universidade Estadual de Campinas, Instituto de Biologia. \\ E-mail para contato: alessandrocoradini@ hotmail.com
}

\begin{abstract}
RESUMO - A levedura Lipomyces starkeyi apresenta uma grande propensão ao acúmulo de triacilgliceróis, utilizando diferentes fontes de carbono (Xilose, Glicose, e outros resíduos) tornando-a um potencial alvo para produção de óleos microbianos. Utilizando como base o genoma da levedura, previamente sequenciado por nosso grupo (dados ainda não publicados), foram selecionados 9 genes relacionados ao metabolismo de xilose para análise do nível de expressão gênico destes durante o processo fermentativo. Foram realizados cultivos em frascos agitados com diferentes fontes de carbono, glicose (controle), xilose além da técnica de Real-Time PCR para análise da expressão gênica. Os dados mostram que os genes Xilose redutase (XYL1); Xilose desidrogenase (XylB); Xilonolactanase (XylC); Xilonato desidratase (XylD) se apresentaram induzidos durante as fermentações na presença de xilose, sendo os 3 últimos presentes em uma via alternativa de degradação de xilose, que parece restrita a alguns poucos grupos de bactérias, na qual através de 4 ou 5 passos enzimáticos a xilose pode ser oxidada gerando piruvato e/ou oxoglutarato. Os resultados também mostram o papel importante dos genes da via das pentoses fosfato (ZWF1, GND1 e PGI1) na assimilação de xilose.
\end{abstract}

\section{INTRODUÇÃO}

As diferentes espécies de Lipomyces apresentam uma grande propensão ao acúmulo de triacilgliceróis. Sua capacidade de produzir lípideos utilizando diferentes fontes de carbono, tais como, xilose, etanol, e a L-arabinose, ou usando uma mistura de glicose/xilose (Zhao et al., 2008, Tapia et al., 2012, Anschau et al., 2014) e xilose/celobiose (Gong et al., 2012), bem como outros resíduos (Angerbauer et al., 2008) tornaram a levedura Lipomyces starkeyi um potencial alvo para produção de óleos microbianos.

Materiais lignocelulósicos contendo celulose, hemicelulose e lignina são recursos orgânicos renováveis abundantes, que podem ser utilizados para a produção de energia e produtos bioquímicos (Weber et al., 2010). Entre 23\% e 40\% da biomassa lignocelulósica é constituída de hemicelulose, sendo seu principal componente a xilose (Jin et al., 2003).

A via da pentose fosfato (PPP) é a rota bioquímica para o metabolismo de xilose, sendo encontrada em virtualmente todos os organismos celulares. Em leveduras, fungos filamentosos e outros eucariotos, a conversão de xilose em xilose $5 \mathrm{P}$ acontece em dois passos, 
via uma redução e posterior oxidação, que são mediadas pelas enzimas xilose redutase (XYL1, Xyl1p) e xilitol desidrogenase (XYL2, Xyl2p), respectivamente (Jeffries et al., 2007).

Existem pelo menos duas outras vias para o catabolismo de xilose que foram descritas apenas em procariotos (Weimberg 1961, Dahms 1974, Stephens et al., 2007). Comum nestas duas vias é o fato da xilose ser oxidada pela enzima xilose desidrogenase (XylB). Em seguida a molécula de Xilonolactona é convertida em Xilonato pela enzima xilonolactanse (XylC). Na terceira etapa Xilonato é metabolizado, pela enzima xilose desidratase (XylD), em 2-Dehidro-3-Deoxi-Xilonato. Está molécula pode seguir duas vias distintas, na primeira conhecida como via de Dahm, a molécula é metabolizada em Piruvato e Gliceraldeído pela enzima 2-Dehidro-3-Deoxi-Xilonato aldolase (KDXA), enquanto na outra via a mesma molécula é convertida em 2-oxoglutarato e redirecionada para o Ciclo do Ácido Cítrico(Stephens et al., 2007).Porém, esta rota que parece atípica de fungos e outros eucariotos, está presente em espécies de bacterias como Pseudomonas, Gluconobacter ssp, Caulobacter crescentus e Haloarcula marismortui (Toivari et al., 2010). Recentemente, leveduras como Saccharomyces cerevisae e Kluyveromyces lactis, foram geneticamente modificadas para a produção de Ácido Xilônico, através da inserção de genes que codificam a enzima XylB obtida do fungo Trichoderma reesei (Toivari et al., 2012).

\section{MATERIAIS E MÉTODOS}

\subsection{MATERIAL BIOLÓGICO E MEIO DE CULTIVO}

Foi utilizada no experimento a linhagem de levedura oleaginosa Lipomyces starkeyi DSM70826. Para o pré-inóculo foram utilizados o meio YPD, para posterior fermentação em Glicose, e o meio YPX -para posterior fermentação em Xilose. Os meios contendo o pré-inóculo foram incubados em agitador orbital (Shell Lab, USA) a $28^{\circ} \mathrm{C}$ e 250 rpm até atingirem a $\mathrm{OD}=0,4$ numa diluição de 50x.

O meio de inóculo foi preparado contendo $30 \mathrm{~g} / \mathrm{L}$ de carboidrato, sendo Glicose para o meio GSM e Xilose para o meio XSM, além de $0,4 \mathrm{~g} / \mathrm{L}$ de $\mathrm{MgSO}_{4}, 0,7 \mathrm{~g} / \mathrm{L}$ de $\mathrm{NH}_{4} \mathrm{SO}_{4}$, $3,5 \mathrm{~g} / \mathrm{L}$ de $\mathrm{KH}_{2} \mathrm{PO}_{4}, 1,0 \mathrm{~g} / \mathrm{L}$ de $\mathrm{Na}_{2} \mathrm{HPO}_{4}, 0.04 \mathrm{~g} / \mathrm{L}$ de $\mathrm{CaCl}_{2}, 0,08 \mathrm{~g} / \mathrm{L}$ de $\mathrm{ZnSO}_{4}, 0,001 \mathrm{~g} / \mathrm{L}$ de $\mathrm{CuSO}_{4}, 0,001 \mathrm{~g} / \mathrm{L}$ de $\mathrm{CoCl}_{2}, 0,001 \mathrm{~g} / \mathrm{L}$ de molibdato de amônio e 0,005 g/L de $\mathrm{MnSO}_{4}$. Sendo o cultivo realizado com relação $\mathrm{C} / \mathrm{N}=50$.

O cultivo foi realizado em meio contendo $10 \%$ de inóculo, sendo posteriormente colocados em agitador orbital a $28^{\circ} \mathrm{C}$ e $200 \mathrm{rpm}$ de agitação. Cabe salientar que os ensaios foram realizados em duplicata biológica e as amostras foram coletadas periodicamente, em intervalos de 24 horas, iniciando no tempo 0h até o tempo $96 \mathrm{~h}$.

\subsection{METODOLOGIA ANALÍTICA}

Uma curva de crescimento de microrganismo foi construída relacionando leituras de diluição de biomassa e concentração por absorbância a $600 \mathrm{~nm}$ numa faixa de 0.1 a 0.6 
utilizando leitora de placas (Multilabel Plate Reader VICTOR X4). Uma curva padrão foi construída utilizando concentrações conhecidas de biomassa.

O consumo de açúcar no meio de cultura foi analisado por cromatografia como descrito por Tapia et al., (2012). A extração de lipídeos foi baseada no método gravimétrico de Bligh \& Dyer, (1959) modificado por Manirakiza e colaboradores (Manirakiza et al., 2001). A concentração residual de nitrogênio no meio de cultura foi estimada usando a reação de Berthelot e medindo o produto de reação a $630 \mathrm{~nm}$. Uma curva de calibração foi construída com diferentes concentrações de sulfato de amónio (5-60 mg / L de N-NH4) de acordo com Tapia et al., (2012).

\subsection{REAÇÃO DE REAL-TIME PCR}

Para extração de RNA, a biomassa foi coletada, congelada imediatamente em nitrogênio líquido e posteriormente acondicionada em biofreezer a $-80^{\circ} \mathrm{C}$ até o momento da extração. A separação de ácidos nucleicos foi realizada pela metodologia de Fenol ácido quente segundo Lin et al, 1996. Para elucidação da correta extração das amostras de RNA, as mesmas foram submetidas à quantificação em aparelho Nanodrop (Thermo scientific, USA) e corrida eletroforética em gel de agarose. A reação procedeu-se em termociclador StepOnePlus ${ }^{\mathrm{TM}}$ Real-Time PCR (Applied Biosystem®, USA).

A análise dos dados obtidos, bem como as análises estatísticas, foram feitasfoi feita utilizando o software REST ®: Relative Expression Software Tool (Pfaffl et al., 2001), sendo que as análises estatísticas foram realizadas com um intervalo de confiança $p<0,1$.

\subsection{ESCOLHA DOS GENES CANDIDATOS.}

Os genes candidatos foram selecionados de acordo com sua função em rotas metabólicas consideradas essenciais para o metabolismo de xilose em leveduras, segundo estudos presentes na literatura (Kruger and von Schaewen 2003, Jeffries et al., 2007, Stephens et al., 2007, Liu et al., 2011, Toivari et al., 2012) e utilizando como base o genoma da levedura L. starkeyi previamente sequenciado pelo nosso grupo de pesquisa. Sendo selecionados os genes ligados a via alternativa de metabolismo de xilose descrita anteriormente (XylB, XylC e XylD), o gene XYL1 da via usual de metabolismo de xilose em eucariotos, os genes GND1 (6-fosfogliconato desidrogenase), ZWF1 (Glicose-6-fosfato desidrogenase), PGI1 (Gliconolactanase) presentes na via das pentoses fosfato além dos genes HXK1 (hexoquinase) e PGK (fosfogliceratoquinase) presentes na via glicolítica. Foram testados 3 genes para a condição de genes de referência, ACT1, UBC6 e RPS26A. Estes 3 genes foram escolhidos devido a sua ampla utilização como genes normalizadores em experimentos envolvendo a técnica de Real-time PCR (Tang et al., 2009, Teste et al., 2009).

\section{RESULTADOS E DISCUSSÃO.}




\subsection{RESULTADOS DOS PARÂMETROS DE CULTIVO EM GLICOSE E XILOSE.}

As figuras 1 e 2 a seguir mostram os resultados das fermentações em glicose e xilose, quanto ao perfil de consumo de nitrogênio e açúcares, bem como a formação de biomassa e lipídeos.

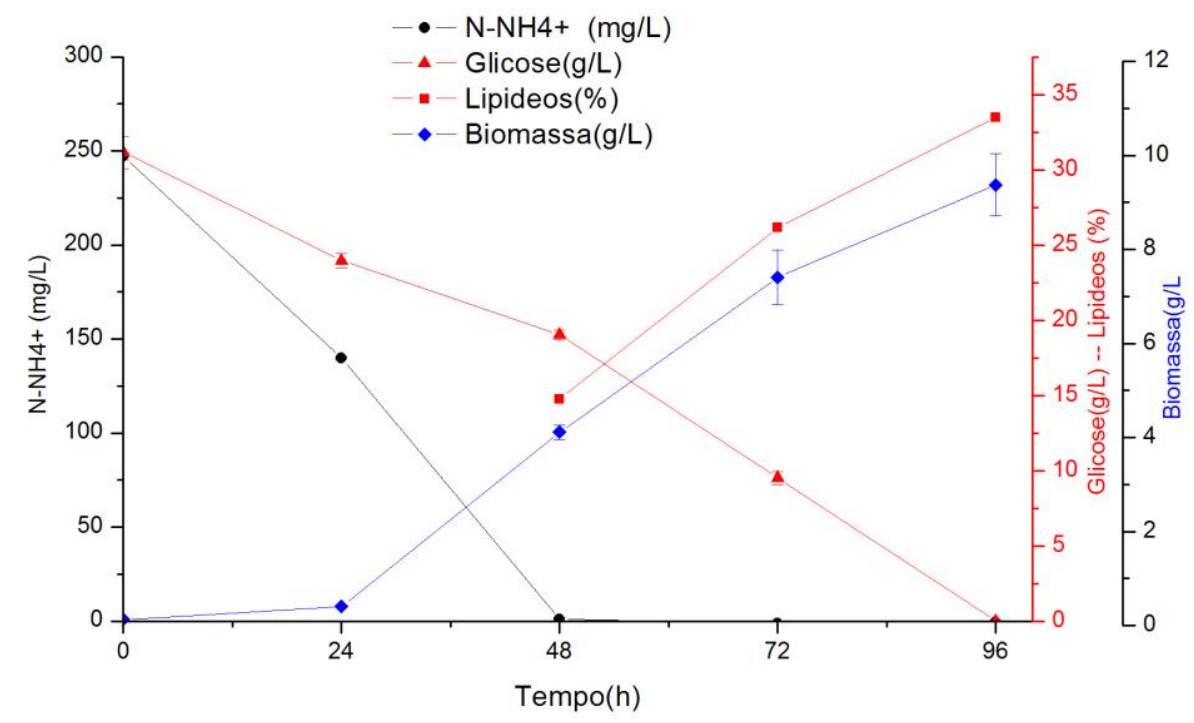

Figura 1: Parâmetros de concentração de biomassa e lipídeos, além de consumo de glicose e nitrogênio para fermentação em glicose.

O acúmulo de lipídeos foi mensurado a partir das $48 \mathrm{~h}$, pois utilizando o método Bligh-Dyer para quantificação de lipídeos, é necessária uma quantidade mínima de 200mg de biomassa, não atingida nos tempos anteriores.

Com relação a concentração final de biomassa e lipídeos, observaram-se os valores de 10,860 g/L e 3,637 g/L, respectivamente, sendo que a concentração de lipídeos corresponde a um percentual em massa de 33,49\% em relação ao peso seco de biomassa. 


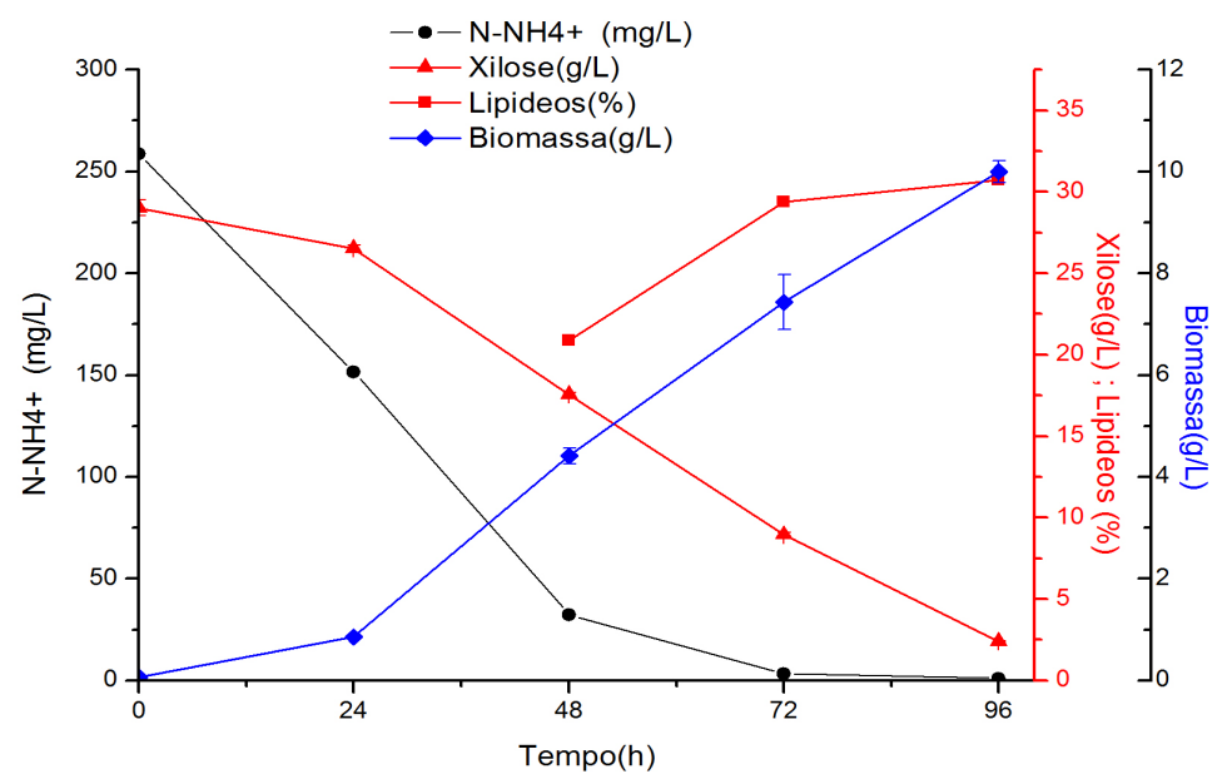

Figura 2: Parâmetros de concentração de biomassa e lipídeos, além de consumo de xilose e nitrogênio para fermentação em Xilose.

Assim como na fermentação em glicose, o acúmulo de lipídeo só pôde ser mensurado a partir das $48 \mathrm{~h}$, pelos mesmos motivos expostos anteriormente. Observou-se uma concentração final de biomassa de $10,590 \mathrm{~g} / \mathrm{L}$. Com relação ao acúmulo final de lipídeos observou-se uma concentração final de $3,253 \mathrm{~g} / \mathrm{L}$, que corresponde a um percentual de $30,71 \%$ do peso total da biomassa seca.

\subsection{ANÁLISE DA EXPRESSÃO RELATIVA DOS GENES LIGADOS AO METABOLISMO DE XILOSE.}

Dos 3 possíveis genes normalizadores testados, aquele que se mostrou mais eficiente e com menor oscilação quanto aos valores de $\mathrm{Ct}$ ao longo da fermentação, bem como nas 2 diferentes condições de cultivo foi o gene ACT1(18,256 $\pm 0,59)$. Portanto este gene foi o escolhido como gene de referência para análise dos demais.

A tabela 1 mostra os valores relativos de expressão dos genes ligados ao metabolismo de xilose para a fermentação em meio contendo xilose como fonte de carbono. Os valores com sinal de negativo demonstram que os genes estão reprimidos enquanto os valores positivos significam que o gene se encontra induzido quando comparados aos mesmos tempos da fermentação em glicose. 
Tabela 1: Resultados da expressão relativa dos genes durante a fermentação em xilose.

\begin{tabular}{ccccc} 
& \multicolumn{4}{c}{ Expressão relativa $(\log )$} \\
\cline { 2 - 5 } Genes & $24 \mathrm{~h}$ & $48 \mathrm{~h}$ & $72 \mathrm{~h}$ & $96 \mathrm{~h}$ \\
\hline \hline XylC & $1,62 \pm 0,4$ & $1,13 \pm 0,26^{*}$ & $1,89 \pm 0,42^{*}$ & $3,29 \pm 1,02^{*}$ \\
XylD & $-0,12 \pm 0,03$ & $0,26 \pm 0,06$ & $1,07 \pm 0,43$ & $1,85 \pm 0,65^{*}$ \\
XYL1 & $5,18 \pm 1,45^{*}$ & $4,70 \pm 1,08^{*}$ & $3,81 \pm 1,15^{*}$ & $3,92 \pm 1,10^{*}$ \\
XylB(1) & $5,78 \pm 1,53^{*}$ & $4,65 \pm 1,43^{*}$ & $4,51 \pm 1,18^{*}$ & $4,37 \pm 1,21^{*}$ \\
XylB(2) & $6,17 \pm 1,44^{*}$ & $4,53 \pm 1,37^{*}$ & $2,93 \pm 0,78^{*}$ & $4,90 \pm 1,45^{*}$ \\
PGK1 & $1,10 \pm 0,52$ & $-1,17 \pm 0,02^{*}$ & $0,50 \pm 0,06$ & $-0,95 \pm 0,02^{*}$ \\
GND1 & $1,64 \pm 0,02^{*}$ & $1,96 \pm 0,38^{*}$ & $-0,04 \pm 0,01$ & $-0,20 \pm 0,03$ \\
PGI1 & $0,59 \pm 0,20$ & $1,30 \pm 0,35^{*}$ & $-0,35 \pm 0,16$ & $-0,80 \pm 0,18$ \\
HXK1 & $-0,60 \pm 0,07$ & $0,11 \pm 0,04$ & $0,80 \pm 0,34$ & $-0,06 \pm 0,03$ \\
\hline
\end{tabular}

*Dados estatisticamente significativos $\mathrm{P}<0,1$

Observando apenas os valores destacados com asterisco, é possível observar que os genes Xilose redutase (XYL1) e as duas cópias do gene Xylose desidrogenase (XylB) estão induzidos em relação a fermentação em glicose, durante todo o processo fermentativo. Além destes os genes Xilonolactanse (XylC) e Xilonato desidratase (XylD) também aparecem como induzido, sendo o primeiro nos tempo 48h, $72 \mathrm{~h}$ e $96 \mathrm{~h}$ e o segundo nos tempos $72 \mathrm{~h}$ e $96 \mathrm{~h}$.

Estes dados corroboram com os dados preditos durante a análise genômica da levedura Lipomyces starkeyi, demonstrando que os genes preditos como sendo XylB, XylC e XylD estão presentes no genoma da levedura e como proposto participam ativamente do metabolismo de xilose. É interessante observar que os valores de expressão são próximos durante toda a fermentação para os genes XYL1 e XylB, o que indica que eles podem estar sendo co-expressos. As cópias dos genes xilose desidrogenase (XylB), por usarem preferencialmente o co-fator $\mathrm{NADP}+$, seriam responsáveis por regenerar o co-fator NADPH utilizado pela enzima xilose redutase (Xyl1p), (Suzuki and Onishi 1973, Berghall et al., 2007, Toivari et al., 2012). Em bactérias, esta rota alternativa de degradação de xilose, é estudada devido a sua utilização industrial visando a produção de D-xilonato, conhecido industrialmente como ácido xilônico (Toivari et al., 2012).

Poucos estudos reportam a presença deste gene em eucariotos (Suzuki and Onishi 1973, Kanauchi and Bamforth 2003). Assim, a presença deste gene expresso na levedura Lipomyces starkeyi representa uma importante fonte de estudos futuros, uma vez que são raríssimos os relatos da presença de enzimas capazes de desidrogenar açúcares (Twerdochlib et al., 1994, Tsai et al., 1995, Kim et al., 1998, Elshafei and Abdel-Fatah 2001). Uma vez que essa levedura apresenta comportamentos fermentativos peculiares, como o consumo simultâneo de glicose e xilose e consumo de inibidores tradicionais gerados durante a hidrólise ácida do bagaço (trabalho em andamento em nosso laboratório), é possível que a presença de vias alternativas incomuns como esta esteja por trás destas particularidades da espécie.

No caso dos genes ligados à via das pentoses fosfato (PPP), que é conhecidamente mais ativa durante o metabolismo de xilose (Jeffries et al., 2007) foi possível observar que os 
genes GND1 e PGI1 (Gluconolactanase) também estão induzidos, nos tempos em que a xilose está sendo consumida (24h e $48 \mathrm{~h}$ ). O gene GND1 faz parte da fase oxidativa da via PPP e responsável por um dos principais pontos de regeneração do cofator NADPH, o qual é utilizado pela enzima xilose redutase no $1^{\circ}$ passo do metabolismo de xilose. Já a maior expressão relativa do gene PGI1 possivelmente está ligada à sua função na produção de Frutose-6-Fosfato, que participa no desvio do fluxo da glicólise para via PPP.

\section{CONCLUSÃO.}

As análises transcriptômicas mostraram que os genes XYL1, XylB, XylC e XylD participam do processo de metabolismo de xilose, uma vez que todos se apresentaram induzidos quando comparados a fermentação onde a fonte de carbono era a glicose. Enquanto o gene XYL1 é conhecido por fazer parte da via principal de metabolismo de xilose em fungos e leveduras, os demais (XylB, XylC e XylD) fazem parte de uma via não usual de metabolismo de xilose em leveduras, que necessita de estudos adicionais á fim de entender qual seu verdadeiro papel no consumo de xilose. Além destes a análise também mostrou o papel importante que os genes da via das pentoses fosfato (ZWF1, GND1 e PGI1) desempenham durante o consumo de xilose. Todos estes genes se mostram importantes fontes de estudo para entendimento do funcionamento metabólico da levedura Lipomyces starkeyi e suas importantes características biológicas, tais como consumo de xilose, inibidores e propensão ao acúmulo de lipídeos. Além disso, estes mesmos genes podem se tornar alvos de interesse para manipulação genética da levedura em questão ou até mesmo para clonagem em outras espécies.

\section{AGRADECIMENTOS}

Agradecemos ao suporte financeiro fornecido pela CNPq e Capes.

\section{REFERÊNCIAS}

Angerbauer, C., M. Siebenhofer, M. Mittelbach and G. M. Guebitz. "Conversion of sewage sludge into lipids by Lipomyces starkeyi for biodiesel production." Bioresource Technology 99(8): 3051-3056.(2008).

Anschau, A., M. C. Xavier, S. Hernalsteens and T. T. Franco. "Effect of feeding strategies on lipid production by Lipomyces starkeyi." Bioresour Technol 157C: 214-222.(2014).

Berghall, S., S. Hilditch, M. Penttila and P. Richard. "Identification in the mould Hypocrea jecorina of a gene encoding an NADP(+): d-xylose dehydrogenase." FEMS Microbiol Lett 277(2): 249-253.(2007).

Bligh, E. G. and W. J. Dyer. "A rapid method of total lipid extraction and purification." Canadian Journal of Biochemistry and Physiology 37(8): 911-917.(1959).

Dahms, A. S. "New Pathway for D-Xylose Metabolism." Federation Proceedings 33(5): 1560-1560.(1974). 
Elshafei, A. M. and 0. M. Abdel-Fatah. "Evidence for a non-phosphorylated route of galactose breakdown in cell-free extracts of Aspergillus niger." Enzyme Microb Technol 29(1): 76-83.(2001).

Gong, Z. W., Q. Wang, H. W. Shen, C. M. Hu, G. J. Jin and Z. B. K. Zhao. "Co-fermentation of cellobiose and xylose by Lipomyces starkeyi for lipid production." Bioresource Technology 117: 20-24.(2012).

Jeffries, T. W., I. V. Grigoriev, J. Grimwood, J. M. Laplaza, A. Aerts, A. Salamov, J. Schmutz, E. Lindquist, P. Dehal, H. Shapiro, Y. S. Jin, V. Passoth and P. M. Richardson. "Genome sequence of the lignocellulose-bioconverting and xylose-fermenting yeast Pichia stipitis." Nature Biotechnology 25(3): 319-326.(2007).

Jin, Y. S., H. Ni, J. M. Laplaza and T. W. Jeffries. "Optimal growth and ethanol production from xylose by recombinant Saccharomyces cerevisiae require moderate D-xylulokinase activity." Appl Environ Microbiol 69(1): 495-503.(2003).

Kanauchi, M. and C. W. Bamforth. "Use of xylose dehydrogenase from Trichoderma viride in an enzymic method for the measurement of pentosan in barley." Journal of the Institute of Brewing 109(3): 203-207.(2003).

Kim, S. T., W. K. Huh, B. H. Lee and S. O. Kang. "D-arabinose dehydrogenase and its gene from Saccharomyces cerevisiae." Biochim Biophys Acta 1429(1): 29-39.(1998).

Kruger, N. J. and A. von Schaewen. "The oxidative pentose phosphate pathway: structure and organisation." Curr Opin Plant Biol 6(3): 236-246.(2003).

Liu, H., X. Zhao, F. Wang, X. Jiang, S. Zhang, M. Ye, Z. K. Zhao and H. Zou. "The proteome analysis of oleaginous yeast Lipomyces starkeyi." Fems Yeast Research 11(1): 4251.(2011).

Manirakiza, P., A. Covaci and P. Schepens. "Comparative study on total lipid determination using Soxhlet, Roese-Gottlieb, Bligh \& Dyer, and modified Bligh \& Dyer extraction methods." Journal of Food Composition and Analysis 14(1): 93-100.(2001).

Stephens, C., B. Christen, T. Fuchs, V. Sundaram, K. Watanabe and U. Jenal. "Genetic analysis of a novel pathway for D-xylose metabolism in Caulobacter crescentus." Journal of Bacteriology 189(5): 2181-2185.(2007).

Stephens, C., B. Christen, T. Fuchs, V. Sundaram, K. Watanabe and U. Jenal. "Genetic analysis of a novel pathway for D-xylose metabolism in Caulobacter crescentus." Journal of Bacteriology 189(5): 2181-2185.(2007).

Suzuki, T. and H. Onishi. "Oxidation and Reduction of D-Xylose by Cell-Free Extract of Pichia-Quercuum." Applied Microbiology 25(5): 850-852.(1973).

Tang, W., S. F. Zhang, Q. Wang, H. D. Tan and Z. K. Zhao. "The isocitrate dehydrogenase gene of oleaginous yeast Lipomyces starkeyi is linked to lipid accumulation." Canadian Journal of Microbiology 55(9): 1062-1069.(2009).

Tapia, V. E., A. Anschau, A. L. Coradini, T. F. T and A. C. Deckmann. "Optimization of lipid production by the oleaginous yeast Lipomyces starkeyi by random mutagenesis coupled to cerulenin screening." AMB Express 2(1): 64.(2012).

Teste, M. A., M. Duquenne, J. M. Francois and J. L. Parrou. "Validation of reference genes for quantitative expression analysis by real-time RT-PCR in Saccharomyces cerevisiae." Bmc Molecular Biology 10.(2009).

Toivari, M., Y. Nygard, E. P. Kumpula, M. L. Vehkomaki, M. Bencina, M. Valkonen, H. Maaheimo, M. Andberg, A. Koivula, L. Ruohonen, M. Penttila and M. G. Wiebe. "Metabolic 
engineering of Saccharomyces cerevisiae for bioconversion of D-xylose to D-xylonate." Metabolic Engineering 14(4): 427-436.(2012).

Toivari, M. H., Y. Nygard, M. Penttila, L. Ruohonen and M. G. Wiebe. "Microbial D-xylonate production." Applied Microbiology and Biotechnology 96(1): 1-8.(2012).

Toivari, M. H., L. Ruohonen, P. Richard, M. Penttila and M. G. Wiebe. "Saccharomyces cerevisiae engineered to produce D-xylonate." Applied Microbiology and Biotechnology 88(3): 751-760.(2010).

Tsai, C. S., J. L. Shi and H. G. Ye. "Kinetic studies of gluconate pathway enzymes from Schizosaccharomyces pombe." Arch Biochem Biophys 316(1): 163-168.(1995).

Twerdochlib, A. L., F. O. Pedrosa, S. Funayama and L. U. Rigo. "L-Rhamnose Metabolism in Pichia-Stipitis and Debaryomyces-Polymorphus." Canadian Journal of Microbiology 40(11): 896-902.(1994).

Weber, C., A. Farwick, F. Benisch, D. Brat, H. Dietz, T. Subtil and E. Boles. "Trends and challenges in the microbial production of lignocellulosic bioalcohol fuels." Applied Microbiology and Biotechnology 87(4): 1303-1315.(2010).

Weimberg, R. "Pentose Oxidation by Pseudomonas Fragi." Journal of Biological Chemistry 236(3): 629-\&.(1961).

Zhao, X., X. L. Kong, Y. Y. Hua, B. Feng and Z. B. Zhao. "Medium optimization for lipid production through co-fermentation of glucose and xylose by the oleaginous yeast Lipomyces starkeyi." European Journal of Lipid Science and Technology 110(5): 405412.(2008). 